\title{
Medical ethics in sub-Sahara Africa: closing the gaps.
}

\author{
Kehinde F. Monsudi ${ }^{1}$, Tajudeen O. Oladele ${ }^{2}$, Abdulrasheed A. Nasir ${ }^{3}$, Abdulkabir A. Ayanniyi ${ }^{4}$
}

1. Department of Ophthalmology, Federal Medical Center, Birnin Kebbi, Nigeria

2. Department of Psychiatric, Federal Neuropsychiatric Hospital, Kware, Nigeria

3. Department of Surgery, University of Ilorin / University of Ilorin Teaching

Hospital, Ilorin, Nigeria

4. Department of Ophthalmology, University of Abuja/ University of Abuja Teaching Hospital, Abuja Nigeria

\begin{abstract}
s
Background: Health care providers are expected to have the skills and knowledge relevant to their field and should also be familiar with the ethical and legal expectations that arise out of the standard practices.

Objectives: To elucidate the practice of the health care providers in relation to healthcare ethics in Nigeria.

Methods: A self-administered structured questionnaire was devised and distributed to staff of two tertiary health care facilities in Northern Nigeria. The questionnaire comprised of detailed questions regarding day-to-day aspects of Medical ethical issues.

Results: A total of $307(76.2 \%$ ) out of 403 health care providers responded to the questionnaire. The median age of the respondents was 34 years. More than half $168(54.7 \%)$ of the respondents disagreed as to whether "Ethical conduct is important only to avoid legal action. Many respondents 135 (44.0\%) agreed to adhering to "patient's wishes", on the other hand over two-third of the respondents $211(68.7 \%)$ agreed that "doctor should do what is best" irrespective of the patient's opinion. There were significant differences $(\mathrm{p}<0.05)$ between the perception of physicians and non-physicians on many ethical issues.

Conclusion: This study has shown gap in knowledge and practice of healthcare ethics among health care providers. There is a need for periodic education on clinical ethics in our hospitals.
\end{abstract}

Keywords: Medical ethics, sub-Sahara Africa.

DOI: http://dx.doi.org/10.4314/ahs.v15i2.47

\section{Introduction}

Ethics is the application of values and moral rules to human activities. Health care providers are expected to not only have the skills and knowledge relevant to their field but also with the ethical and legal expectations that arise out of the standard practices. ${ }^{1}$ Medical ethics has been founded on the framework of four moral principles of autonomy, beneficence, nonmaleficence, and justice. $^{2}$ The first of these principles, autonomy, is the respect for the patient's right to self-governance, choice in care, and the right to accept or refuse treatment. Be-

\section{Corresponding author: \\ Abdulrasheed A. Nasir \\ Department of Surgery, University of \\ Ilorin / University of Ilorin Teaching \\ Hospital, Ilorin, Nigeria \\ Email: draanasir@yahoo.com}

neficence is the obligation to prevent or remove harm while also promoting good by contributing to the welfare and acting in the best interest of the patient. Nonmaleficence implies the obligation of physicians not to inflict harm or adverse effects on the patient from inappropriate or absent care (This principle involves consideration of risks versus benefits from particular procedures). The last ethical principle, justice means distributing benefits, risks, and costs fairly, equitably, and appropriately, and treating patients with similar cases in a similar manner ${ }^{3,4}$

There has been growing public concern regarding the ethical conduct of healthcare professionals. This often manifests as complaints about poor ethical conduct and an increasing use of litigation against healthcare practitioners. ${ }^{5}$ The recent increase in number of court cases against hospital workers in Nigeria may reflect gaps in their level of awareness and basic knowledge of medical ethics. All health care workers have a moral obligation to help their patients and the society. It is generally held that physicians should always act in the best inter- 
est of their patients; but sometimes there is a conflict administered and divided into two sections. The section between obligations to a patient and those perceived to be owed to the community or to other patients. For as tribe, education level, occupation, age, gender an instance should a doctor discloses the HIV status of a duration of the working experience and how often an non consenting spouse to the partner or notify the po- ethical or legal problem is encountered in their practice. lice of a wounded armed robber in doctor's care.

Traditional training offers little help in resolving the ethical dilemmas encountered by physicians. Even among other healthcare professionals there has been no effort to teach ethics and law as separate courses incorporated into the curriculum. ${ }^{5}$ In order to formulate ethical curriculum relevant to every region, it is pertinent to determine the current basic knowledge and attitudes of the healthcare practitioners in the region. There have been few studies designed to measure what is known and practiced in Nigeria, so that educational efforts may be better targeted.

This background forms the basis of the present stud with an attempt to elucidate the knowledge, attitude and practice of the health care providers in relation to health care ethics in Nigeria. We hypothesized that health care ethics are deficient in the health care setting.

\section{Methods}

This was a descriptive, cross-sectional study among healthcare providers in two government tertiary hospital in Northern Nigeria. Approval was sought from the Hospital ethics review committees of these institutions prior to the study. Participation was completely voluntary. All information collected for this study was anonymous and responses were treated as confidential.

The study was conducted using structured questionnaires, adopted from previous study by Hariharan et al., ${ }^{6}$ The questionnaire was designed to examine the staff decision-making process in relation to ethical and legal problems and to identify the healthcare practitioner's values, beliefs and attitudes. The questionnaire was self
On the other side the section B of the questionnaire consisted of respondent's view about questions regarding day-to-day practice of ethics (Appendix 1).

The respondents were divided into two groups for purpose of analysis. One group consisting of physician and the other of all other service providers in the same setting who would come in contact with patients -- these include nurses, pharmacists, physiotherapists, administrators, medical record officers, laboratory scientist and technicians, social workers, clerks and technician The responses were based on a 5 point Likert scale: 1 strongly disagree, 2-disagree, 3-not sure, 4-agree and 5-srongly agree.

\section{Data analysis}

Descriptive analysis was carried out using SPSS version 15.0 (SPSS, Inc, Chicago, IL). The responses of the five point Likert scale were grouped into three: Strongly agree and agree as agree; disagree and strongly disagree as disagree; and the other group was those unsure. Dat was quoted as median (interquartile range). The two groups were compared using Pearson's Chi-square tes or Fisher's Exact test (as appropriate). $\mathrm{P}<0.05$ was conidered as statistically significant.

\section{Results}

A total of 307 out of 403 health care providers from various departments responded to the questionnaire $(76.2 \%$ response rate). There were $216(70.4 \%)$ men and $91(29.6 \%)$ women. There were 37 physicians and 270 non-physician health care providers. The demoThe characteristics of the respondents are given in Table 1.
Table 1: Demographics Characteristics of respondents

\begin{tabular}{|c|c|c|c|}
\hline \multicolumn{2}{|l|}{ Variables } & Number & $\%$ \\
\hline \multirow[t]{2}{*}{ Gender } & Male & 216 & 70.4 \\
\hline & Female & 91 & 29.6 \\
\hline \multirow[t]{4}{*}{ Age in years } & $<25$ & 18 & 5.9 \\
\hline & $25-34$ & 141 & 45.9 \\
\hline & $35-44$ & 93 & 31.3 \\
\hline & $\geq 45$ & 55 & 17.9 \\
\hline \multirow[t]{3}{*}{ Working experience in years } & $<5$ & 150 & 48.9 \\
\hline & $5-10$ & 72 & 23.4 \\
\hline & $>10$ & 85 & 27.7 \\
\hline \multirow[t]{2}{*}{ Categories } & Physicians & 37 & 12.1 \\
\hline & Non- Physicians & 270 & 87.9 \\
\hline \multirow[t]{12}{*}{ Designation } & Nurses & 127 & 41.4 \\
\hline & Physicians & 37 & 12.1 \\
\hline & Laboratory scientist & 29 & 9.4 \\
\hline & Administrative staff & 28 & 9.1 \\
\hline & Laboratory technicians & 17 & 5.5 \\
\hline & Dental technicians & 14 & 4.6 \\
\hline & Account officers & 12 & 3.9 \\
\hline & Medical record officers & 9 & 2.9 \\
\hline & Social workers & 6 & 2.0 \\
\hline & Pharmacist & 4 & 1.3 \\
\hline & Physiotherapist & 4 & 1.3 \\
\hline & ${ }^{*}$ Others & 20 & 6.5 \\
\hline
\end{tabular}

"Laundary staff, information scientist, pharmacy technicians, Nursing aides,legal officers, environment sanitation staff and security officers

The median age of the respondents was 34 (29-41) (44\%) agreed that "During treatment, the patient's wishyears and most respondents $234(77.2 \%)$ were in the age es must always be adhered to." However, 211(68.7\%) range 25-44 years. The median year of working experi- respondents believed that "The doctor should do what ence was 5 (1-12). More than half of the respondents is best irrespective of the patient's opinion" and 229 $157(51.1 \%)$ had working experience of over 5 years. $\quad(74.6 \%)$ of the participants will inform the patients" Table 2 shows the responses of healthcare providers to if something goes wrong." Most of the respondents various ethical scenarios. More than half $168(54.7 \%)$ of $239(77.9 \%)$ disagreed that confidentiality cannot be the respondents disagreed and $128(41.7 \%)$ agreed as kept in modern care and should be abandoned. Howevto whether "Ethical conduct is important only to avoid er, significant number of the respondents $198(64.5 \%)$ legal action." One hundred and thirty five respondents still agreed that close relatives must always be told about patient's condition. 
Table 2: Opinion of healthcare personnel on the different issues of care-ethics $(\mathrm{n}=307)$.

\begin{tabular}{|c|c|c|c|}
\hline Issues in practice of medical ethics & Agree & Disagree & Not sure \\
\hline Ethical conduct is important only to avoid legal action & 128 & 168 & 11 \\
\hline Patient's wishes must always be adhered to' & 135 & 134 & 38 \\
\hline $\begin{array}{l}\text { Doctor should do what is best irrespective of patient's } \\
\text { opinion }\end{array}$ & 211 & 82 & 14 \\
\hline Patient should always be told if something is wrong & 229 & 55 & 23 \\
\hline $\begin{array}{l}\text { Confidentiality cannot be kept in modern care and should } \\
\text { be abandoned }\end{array}$ & 49 & 239 & 19 \\
\hline $\begin{array}{l}\text { Close relatives must always be told about a patient's } \\
\text { condition }\end{array}$ & 198 & 95 & 14 \\
\hline $\begin{array}{l}\text { Patients only need to consent for operations but not for } \\
\text { tests or medications }\end{array}$ & 101 & 191 & 15 \\
\hline $\begin{array}{l}\text { Children should never be treated without the consent of } \\
\text { their parents or guardians' (except in an emergency) }\end{array}$ & 228 & 70 & 9 \\
\hline $\begin{array}{l}\text { Doctors and nurses should refuse to treat patients who } \\
\text { behave violently' }\end{array}$ & 37 & 256 & 14 \\
\hline $\begin{array}{l}\text { If patients refuse treatment due to beliefs, they should be } \\
\text { instructed to find another doctor' }\end{array}$ & 125 & 151 & 31 \\
\hline $\begin{array}{l}\text { 'If the law allows abortion to be performed, a healthcare } \\
\text { worker cannot refuse to do an abortion' }\end{array}$ & 40 & 234 & 33 \\
\hline Patient who wishes to die should be assisted in doing so' & 19 & 267 & 21 \\
\hline $\begin{array}{l}\text { Hospital staff are free to disseminate/publish hospital } \\
\text { information without hospital approval }\end{array}$ & 22 & 274 & 11 \\
\hline $\begin{array}{l}\text { Hospital staff can use patient picture in public forum } \\
\text { without the patient consent }\end{array}$ & 33 & 261 & 13 \\
\hline
\end{tabular}

On whether the children (except in emergency) should will refer the patient to another doctor, if a patient renever be treated without the consent of their parents or fused a particular treatment for religious reasons while guardian, $228(74.3 \%)$ agreed. Two hundred and thirty $31(10 \%)$ of respondents were uncertain on how to deal four $(76.2 \%)$ disagreed to doctor not refusing to abor- with patients who refuse treatment. Comparison of the tion if law permit it, another $267(87 \%)$ disagreed to the responses of physicians and non-physicians on various suggestion of euthanasia and $125(40.7 \%)$ agreed they aspects of the practice of clinical or healthcare ethics is shown in Table 3.

Table 3: Comparison of Practice of Ethics among physician and Non physicians

\begin{tabular}{|c|c|c|c|c|c|}
\hline Issues in practice of medical ethics & Categories & Agree & Disagree & Not sure & P-Value \\
\hline \multirow{2}{*}{$\begin{array}{l}\text { Ethical conduct is important only } \\
\text { to avoid legal action' }\end{array}$} & Physicians & 9 & 26 & 2 & 0.071 \\
\hline & Non-Physicians & 119 & 142 & 9 & \\
\hline \multirow{2}{*}{$\begin{array}{l}\text { Patient's wishes must always be } \\
\text { adhered to' }\end{array}$} & Physicians & 13 & 21 & 3 & 0.221 \\
\hline & Non-Physicians & 122 & 113 & 35 & \\
\hline \multirow{2}{*}{$\begin{array}{l}\text { Doctor should do what is best } \\
\text { irrespective of patient's opinion }\end{array}$} & Physicians & 17 & 19 & 1 & 0.001 \\
\hline & Non-Physicians & 194 & 82 & 14 & \\
\hline \multirow{2}{*}{$\begin{array}{l}\text { Patient should always be told if } \\
\text { something is wrong }\end{array}$} & Physicians & 31 & 6 & 0 & 0.158 \\
\hline & Non-Physicians & 198 & 49 & 23 & \\
\hline \multirow{2}{*}{$\begin{array}{l}\text { Confidentiality cannot be kept in } \\
\text { modern care and should be } \\
\text { abandoned }\end{array}$} & Physicians & 0 & 37 & 0 & 0.003 \\
\hline & Non-Physicians & 49 & 202 & 19 & \\
\hline \multirow{2}{*}{$\begin{array}{l}\text { Close relatives must always be } \\
\text { told about a patient's condition }\end{array}$} & Physicians & 9 & 25 & 3 & $<0.0001$ \\
\hline & Non-Physicians & 189 & 70 & 11 & \\
\hline \multirow{2}{*}{$\begin{array}{l}\text { Patients only need to consent for } \\
\text { operations but not for tests or } \\
\text { medications }\end{array}$} & Physicians & 4 & 31 & 2 & 0.009 \\
\hline & Non-Physicians & 97 & 160 & 13 & \\
\hline \multirow{2}{*}{$\begin{array}{l}\text { Children should never be treated } \\
\text { without the consent of their } \\
\text { parents or guardians' (except in an } \\
\text { emergency) }\end{array}$} & Physicians & 22 & 14 & 1 & 0.066 \\
\hline & Non-Physicians & 206 & 56 & 8 & \\
\hline \multirow{2}{*}{$\begin{array}{l}\text { Doctors and nurses should refuse } \\
\text { to treat patients who behave } \\
\text { violently }\end{array}$} & Physicians & 4 & 31 & 2 & 0.942 \\
\hline & Non-Physicians & 33 & 225 & 12 & \\
\hline \multirow{2}{*}{$\begin{array}{l}\text { If patients refuse treatment due to } \\
\text { beliefs, they should be instructed } \\
\text { to find another doctor' }\end{array}$} & Physicians & 12 & 17 & 8 & 0.042 \\
\hline & Non-Physicians & 113 & 134 & 23 & \\
\hline \multirow{2}{*}{$\begin{array}{l}\text { 'If the law allows abortion to be } \\
\text { performed, a healthcare worker } \\
\text { cannot refuse to do an abortion' }\end{array}$} & Physicians & 4 & 29 & 4 & 0.912 \\
\hline & Non-Physicians & 36 & 205 & 29 & \\
\hline \multirow{2}{*}{$\begin{array}{l}\text { Patient who wishes to die should } \\
\text { be assisted in doing so' }\end{array}$} & Physicians & 1 & 30 & 6 & 0.041 \\
\hline & Non-Physicians & 18 & 237 & 15 & \\
\hline \multirow{2}{*}{$\begin{array}{l}\text { Hospital staff are free to } \\
\text { disseminate/publish hospital } \\
\text { information without hospital } \\
\text { approval }\end{array}$} & Physicians & 0 & 36 & 1 & 0.186 \\
\hline & Non-Physicians & 22 & 238 & 10 & \\
\hline \multirow{2}{*}{$\begin{array}{l}\text { Hospital staff can use patient } \\
\text { picture in public forum without } \\
\text { the patient consent }\end{array}$} & Physicians & 1 & 35 & 1 & 0.200 \\
\hline & Non-Physicians & 32 & 226 & 12 & \\
\hline
\end{tabular}


There were significant differences $(\mathrm{p}<0.05)$ between the perception of physicians and non-physicians on whether they will always inform close relatives abou the patient's condition, whether they did what is best for the patient irrespective of the patient's opinion, and whether they will refer patient to another doctor, if a patient refused a particular treatment on religious ground.The response of the physicians and non-physicians also significantly differ on whether patients only need to consent for operations but not for tests or medications, and whether they will agreed with patients who requested their help in dying, and maintaining confidentiality. There were no significant differences in the opinions of physicians and non-physicians regarding other issues such as whether ethical conduct is only important to avoid legal action; whether they considered patients wishes before taking major decisions on their care; and whether they refused to treat violent patients.

Respondents views were similar on whether they will inform patient when something is wrong, whether they would not treat children without the parent's consent, and whether they will not refuse to perform abortion if the law permitted it. Physicians also share similar opinion with non-physicians on whether hospital staff are free to disseminate/publish hospital information without hospital approval and if they can use patient picture in public forum without the patient's consent (Table 3)

Physicians' reported practices in various situations related to ethical practice were highlighted in Table 3. The majority $(70.3 \%, 26 / 37)$ of the physicians disaAll the physicins disagreed that confidentially should be abandoned in modern care. Only few $(24.3 \%, 9 / 37)$ will always inform close relatives about the patient's condition, majority $(59.5 \%, 22 / 37)$ would not treat children without the parent's consent. Seventy-eight percent (29/37) of physicians disagreed that health care worker cannot refuse to perform abortion if the law permitted it. Only $(32.4 \%, 12 / 37)$ stated that if a patient refused a particular treatment for religious reasons, they would refer them to another doctor. Most of the physicians $(81.1 \%, 30 / 37)$ would not assist a patient who wishes to die to do so, and only one $(2.7 \%)$ of the physicians will use patient picture in public forum without the patient consent

This study showed gaps in knowledge of ethics among healthcare workers in our clinical setting. The fact that over $42 \%$ of the respondents agreed that ethics is important only for legal purpose indicates that there is very little knowledge regarding health care ethics in these settings. This is in contrast to similar study among Caribbean health workers where majority of the respondents (94\%) disagree with this view. ${ }^{6}$ This may probably reflect the low level of awareness of health care consumers in sub-Sahara Africa of their rights and of health care providers' obligation to respect those rights. Many of the respondents expressed contradictory views in different areas of ethical issues for instance, many respondents $135(44.0 \%)$ agreed to adhering to "patient's wishes", on the other hand over two-third of the respondents $211(68.7 \%)$ agreed that "doctor should do what is best" irrespective of the patient's opinion.

The findings in this study like similar study in India reflect the paternalistic approach to patient care where physicians are seen like God who knows all. ${ }^{7}$ However, modern medicine seeks to avoid a paternalistic (docto knows best) approach to patients. Instead it consider the doctor and patient mutually engaging in the decision making with the final decision on treatment options being that of the patient. In a related study on attitudes towards patient autonomy, Caribbean health care providers showed a greater commitment to patient autonomy than this report ${ }^{5,6}$ This varied view point among practitioners could have been influenced by the cross-cultural perspectives or exposure to ethical teaching.

The fact that handful of the respondents did not feel that the patient's wishes should be adhered to at all times and majority agreeing that the doctor should always do the best for the patient irrespective of patient opinion, shows the lack of knowledge of the basic principles of medical ethics among the surveyed health care providers. Although, significantly more of the non physician agreed that doctor should do the best for the patient close to half of the physicians also hold the paternalistic view. Respect for patient autonomy and informed consent are crucial to ethical practice and is a moral obligation we owe our patients. This moral obligation may only be breached in exceptional circumstances. The paternalistic approach to patient care may be relevant in emergency conditions or when patients would not be mental ill health or a minor.

In health care practice, respecting people's autonom has many prima facie implications. It requires us to consult people and obtain their agreement before any intervention.

Hence, the obligation to obtain informed consent from patients before offering care to them. ${ }^{8}$ Notwithstanding our aims of offering each patient net benefit, we must respect their autonomy for what constitutes benefit for one patient may be harm for another. This fact has been illustrated with mastectomy for breast cancer. Mastectomy may constitute a prospective net benefit for one woman with breast cancer, while for anothe the destruction of an aspect of her feminine identity may be so harmful that it cannot be outweighed even by the prospect of an extended life expectancy.

It is important to note, that the theory of contemporary medical ethics is a typical American product and it remains a concern whether it will spread globally. There are growing dissenting voices, even in western countrie such as the United Kingdom, regarding the application of the principle of autonomy in medical field which are being supported by an argument that it erodes the trust between the patient and the treating physician. ${ }^{9}$ This may explain why about $44 \%$ of the respondents in the present study did not agree to the view that the patient's wishes should always be adhered to and about a twothird of the respondents agreed to the paternalistic attitude of physicians while treating a patient. This finding is consistent with that of Caribbean study where $45 \%$ of the respor patient's wishes should always be adhered to. ${ }^{6}$ Medical confidentiality is another implication of respecting people's autonomy. Health care workers explicitly or implicitly promise their patients that they will keep confidential the information confided to them as a matter of code of professional conduct. Keeping promises is also a way of respecting people's autonomy. Without such promises of confidentiality patients are also unlikely to divulge the highly private and sensitive information that is needed for their optimal care. ${ }^{8}$

Maintaining patient's confidentiality has always been an ethical dilemma. In the present study, the responses the question regarding confidentiality varied widely. While majority agreed to the view that patient confidentiality is very important and should not be abandoned, almost $65 \%$ of the respondents also opined that patient's relatives should be told of the patient's condition. In a study of 364 health care providers in Queen Elizabeth hospital, Barbados, one-third of the respondents also felt that patient's relatives should be told of the patient's condition. ${ }^{6}$ What is common in these studies is the diverse cultural influence which has been described as the major issues in present day bioethics. ${ }^{8,10,1}$

Health care workers in Africa similar to Asia communities are more likely to be confronted with moral conflicts because of the less demands for self actualization of their people compare to their counterparts in the West. ${ }^{10} \quad$ Traditionally, family and community carry a greater weight in African/Asian value systems than individuals. It will always be difficult not to inform relative of patient's condition, whom in the first instance are likely to bring patient to hospital and also most of the time be responsible for the cost of treatment.

One phenomenon highlighted in previous reports is the difference between East Asian countries and North America/Europe as regard the locus of authority in decision-making: North America/Europe demands and promotes the value of individual autonomy; East Asian countries typically honor and uphold the value of famiy autonomy ${ }^{12,13}$ The philosophy in sub-Saharan African countries is similar to Asian countries. In a well written appraisal of the four principles of medical ethics plus attention to scope by Gillion, ${ }^{8}$ he emphasized the tendency to disagree about scope of application of the principle of ethics especially about to what or to whom we owe these moral obligations. ${ }^{8}$

Interestingly, even if we agree that the scope of the principle of respect for autonomy is universal, encompassing all autonomous agents. The question remains as to who or what counts as an autonomous agent?. ${ }^{8}$ The author however answered the philosophical questions: health care workers should acknowledge that the autonomy of everybody even young children and severely mentally impaired people should prima facie be respected unless there are good moral reasons not to do so and that those reasons should highly be on the context. ${ }^{8}$ From the foregoing, it is clear that the health care eth- 
ics strives to maximize the good by producing the best balance of benefit and harm. It forces us to look at all potential consequences of our decisions. On issue of confidentiality, the ideal ethical practice for health care providers is to consider how best to act in the interest of their patient whilst still respecting the involvement of the family in the decision.

In the present study, significant number of the respondents disagreed that health care workers cannot refuse abortion if law permits it. This finding may reflect the influence of religious values in the respondents. In a similar vein, there was $87 \%$ disagreement for the practice of euthanasia. This finding is consistent with previous studies where overwhelming majority of the respondents voted against abortion and euthanasia. ${ }^{6,14}$

It is important to understand that vast majority of $\mathrm{Ni}$ gerians are staunchly religious people and they value the teachings of their religion more than the secula thoughts. More importantly, this study was conducted in region which is densely populated with Muslims. The main Islamic guiding principles are respect for human dignity and the maintenance and protection of life, property and honor. Because of the unconditional valuation of human life, every additional day lived is of value; a treatment that prolongs life therefore cannot be harmful. The trust in an omnipotent God is a second reason why decisions to forgo life-prolonging treatments cannot be justified. ${ }^{15}$ 'Muslims feel very strong that it is Allah who does the actual healing, the doctor being only the agent for the will of Allah, ${ }^{16}$ just like in Christianity. It has previously been hypothesized that strong religious background may have a profound in fluence in the practice of ethics in a hospital setting, since religion makes a big difference in clinical healthcare delivery to both provider and the patient, although not invariably. ${ }^{6,1}$

Religion and its concomitant sanctity of life position provide support to physicians who hold the belief that death should not be deliberately hastened. ${ }^{18,19}$ Control over life and death (and its timing) is with nature or the divine. ${ }^{20}$ Accordingly, such a position precludes any acceptance of a request to die or any intentional autonomous action of the physician to hasten death. This views cut across broader political, legal and professional positions, and even across specialties. ${ }^{21}$ Contrary views to such commonly accepted positions on hastening death are, however, also provided by some physicians who consider patient choice and autonomy most imtiming of death. Many physicians state that they would not intentionally hasten death regardless of whether it is requested or not, but death sometimes occurs as a consequence of addressing patient suffering. ${ }^{21}$

The findings of this study has demonstrated knowledge gap in health care ethics among both physicians and non-physicians. The fact that varying range of respondents had "no answer" to most of the questions may indicate their lack of awareness or knowledge in that area their inability to decide or commit a specific response, or their disinterest.

Comparing the two groups of health care providers, responses from both physician and non-physicians to questions pertaining to practical ethics were most common ethical issues (Table 3). There were significantly stronger opinions of the physician on issues like with respect to confidentiality, informing relative about patient condition, doctor doing the best for the patient irrespective of patient opinion; consent for procedures and referring noncompliant patients.

There was also a significant difference of opinion between physician and non physician on whether patien who wishes to die should be assisted in doing so. The varying opinions of the respondents in the present study may reflect the difference in the intensity of traning between these professionals and also the degree of interaction with patient.

\section{Limitations}

Participants' practices were self-reported and their resonses may have reflected what they believed were appropriate. The study involved two tertiary hospital in Northern Nigeria, the results may not necessarily be representative to all hospital healthcare providers.

\section{Conclusion}

This study has shown gap in knowledge and practice of healthcare ethics among both physicians and non-physicians in our setting. For the field of healthcare ethics to continuously advance, healthcare workers need to devote more attention to ethical reflection. The study also suggests that most literature and teaching on healthcare ethics emphasize on the so called "western" perspective of ethics which are formulated and applicable to the healthcare profession in the western countries. However, it is necessary to formulate medical ethics within the context of the individual socio-economic, geo-po- bioethics for Asian people. J Med Ethics 2001;27:51-54. litical, religious and cultural background. The need for 11. Kuczewski M, McCruden PJ. Informed Consent: periodic continuing education on clinical ethics utilizing Does it take a Village? The Problem of Culture and a multidisciplinary approach to bridge the gap in ethi- Truth Telling. Cambridge Quarterly of Healthcare Ethcal knowledge and practices between different healthcare personnel cannot be overemphasized. This study should serve as a stimulus to help promote the growt in all areas of ethical discourse.

\section{References:}

. Unnikrishnan B, Kanchan T, Kulkarni V, et al., Perceptions and practices of medical practitioners towards ethics in medical practice - a study from coastal South India. J Forensic Leg Med. 2014; 22:51-6.

2. Beauchamp TL, Childress JF. Principles of biomedical ethics 5th Edition, Oxford University; Oxford: 2001

3. Chung KC, Pushman AG, Bellfi LT. A Systematic Review of Ethical Principles in the Plastic Surgery Literature. Plast Reconstr Surg. 2009;124:1711-18.

4. Kennelly J. Medical ethics: four principles, two decisions, two roles and no reasons. J Prim Health Care 2011;3:170-74.

5. Hariharan S, Jonnalagadda R, Walrond E, et al. Moseley $\mathrm{H}$. Knowledge, attitudes and practice of healthcare ethics and law among doctors and nurses in Barbados. BMC Med Ethics 2006, 7:7.

6. Hariharan S, Jonnalagadda R, Gora J. Knowledge, attitudes and practices of healthcare personnel towards Care-Ethics: A perspective from the Caribbean. The Int $J$ Law, Healthcare and Etbics.2007;5.

. Subramanian TH, Mat hai AK, Kumar N. Knowledge and practice of clinical ethics among healthcare providers in a government hospital, Chennai. Indian Med Ethics 2013;10:96-100.

8. Gillon R Medical ethics: four principles plus attention to scope. Br Med J 1994;309:184-8.

9. Herissone-Kelly P. Bioethics in the United Kingdom: Genetic Screening, Disability Rights and the Erosion of Trust. Cambridge Quarterly of Healthcare Ethics 2003; 12: 235-241.

10. Tai M.C, Lin CS. Developing a culturally relevant ics 2001; 10:34-46

12. Fan R. Self-determination vs. family-determination: two incommensurable principles of autonomy: a report from East Asia. Bioethics 1997,11:309-322.

13. Chen YY, Chu TS, Kao YH, et al., To evaluate the effectiveness of health care ethics consultation based on the goals of health care ethics consultation: a prospective cohort study with randomization. BMC Med Ethics 2014;15:1

14. Walrond ER, Jonnalagadda R, Hariharan S, et al, Knowledge, attitudes and practice of medical students at the Cave Hill Campus in relation to ethics and law in healthcare. West Indian Med J. 2006;55: 42-7.

15. Westra AE, Willems DL, Smit BJ. Communicating with Muslim parents: "the four principles" are not as culturally neutral as suggested. Eur J Pediatr 2009;168:1383-1387.

16. van Bommel A. Medical ethics from the Muslim perspective. Acta Neurochir Suppl (Wien) 1999;74:17-27.

17. Hanson MJ. The religious difference in clinical healthcare. Cambridge Quarterly of Healthcare Ethics 1998;7: 57-67.

18. Biggs $\mathrm{H}$, Ost $\mathrm{S}$. As it is in end so it is at the beginning: legal challenges and new horizons for medicalised death and dying. Med Law Rev 2010;18:437-441.

19. Gormally L. Terminal sedation and the doctrine of the sanctity of life. In Terminal sedation: Euthanasia in disguise?. Edited by Tännsjö T. Dordrecht, Netherlands: Kluwer Academic Publishers;2004:81-91.

20. Bruno M, Ledoux D, Laureys S. The dying human: a perspective from biomedicine. In The Study of Dying: From Autonomy to Transformation. Edited by Kellehear A. Cambridge, UK: Cambridge University Press;2009:51-75.

21. Trankle SA. Decisions that hasten death: double effect and the experiences of physicians in Australia. BMC Medical Ethics 2014; 15:26. 